\title{
Sintonia e amizade entre patrões e donos de morro Perspectivas comparativas entre o comércio varejista de drogas em São Paulo e no Rio de Janeiro
}

\author{
Daniel Veloso Hirata e Carolina Christoph Grillo
}

Introdução

O presente artigo é resultado de uma série de discussões entre os autores, que anteriormente realizaram pesquisas etnográficas sobre as dinâmicas criminais em periferias paulistas e favelas cariocas. Durante essas discussões identificou-se que quase inexistem estudos comparativos entre Rio de Janeiro e São Paulo e então surgiu a ideia de prospectar esse terreno. Um esforço de pesquisa de maior amplitude será desenvolvido por meio de pesquisa conjunta em um projeto iniciado no ano de $2014^{1}$. Para este artigo, o material utilizado refere-se ao trabalho de campo realizado entre 2006 e 2010 em São Paulo e entre 2009 e 2012 no Rio de Janeiro, assim como à revisão de uma série de pesquisas que foram produzidas antes e depois desse período, das quais nos consideramos devedores pelo privilégio do aprendizado e interlocução².

O escopo deste artigo é relativamente restrito, porque pretende apenas salientar algumas dimensões de uma possível comparação da venda de drogas em cada uma

1. Projeto Temático Fapesp "A gestão do conflito na produção da cidade contemporânea: a experiência paulista", coordenado por Vera da Silva Telles.

2. As questões levantadas neste trabalho resultam da valiosa interlocução que tivemos o privilégio de manter, ao longo dos últimos anos, com diversos pesquisadores que se debruçaram sobre os temas aqui abordados, como Michel Misse, Vera da Silva Telles, Antonio Carlos Rafael Barbosa, Luiz Antonio Machado da Silva, Gabriel de Santis Feltran, Adalton Marques, Karina Biondi, Paulo Malvasi, Natasha Elbas Neri, Diogo Lyra, Fábio Mallart, Rafael Godoi, Mariana Cavalcanti, Camila Caldeira Nunes Dias, Márcia Leite, Palloma Menezes, Liniker Batista, Ronaldo Almeida e outros. 
dessas cidades na atualidade. Isso significa que uma série de discussões muito importantes serão mobilizadas apenas e tão somente em função dessa questão mais central, como, por exemplo: Quais as comparações possíveis entre os comandos cariocas e paulistas? Quais as diferenças das políticas de repressão às drogas dos governos estaduais? Parece-nos que essas questões complexas merecem um tratamento pormenorizado e específico em outros textos, fazendo parte de um trabalho coletivo que diversos pesquisadores engajados nesses temas poderiam realizar em vista de produzir um corpus comparativo mais amplo.

É importante destacar preliminarmente que será pouco explorada uma dimensão que cada vez nos parece mais fundamental, eixo mais relevante de nossa pesquisa em curso, que é a análise diacrônica das práticas criminais. Consideramos decisivo prospectar a história social urbana dos mercados criminais em suas relações processuais e dinâmicas (Telles, 2010) com vistas a compreender sua acumulação social (Misse, 2006). Contudo, como primeira exploração comparativa, trabalharemos as dinâmicas vigentes do tráfico de drogas na atualidade, o que nos servirá de guia nas subsequentes incursões históricas.

Nosso ponto de partida crítico são as imagens contidas na representação da violência urbana, que desde a década de 1970 vem constituindo-se como "problema social" e culminou na difusão da "metáfora da guerra” (Leite, 2000) como chave interpretativa para pensar os conflitos urbanos. Segundo Luiz Antonio Machado da Silva (1999; 2008), tal percepção de aumento constante das ações violentas seleciona e indica um complexo de práticas consideradas ameaças à integridade físico-pessoal e ao patrimônio material. Poderíamos acrescentar que essa representação associa de forma direta a existência do mercado de drogas a essas duas ameaças, pois, como apontou Machado da Silva, ela forneceria as bases materiais para a reprodução da violência urbana. Ademais, o tráfico de drogas emerge a partir dos anos de 1980 como a principal expressão da ameaça do chamado "crime organizado", figura contemporânea do inimigo social, ainda que outras formas da criminalidade organizada existissem anteriormente (Misse, 1999).

O que ocorre, como argumenta Antonio Carlos Rafael Barbosa (2005), é que o tráfico de drogas conseguiu organizar o campo dos ilegalismos populares como nenhuma outra atividade criminal, fazendo as demais penderem em sua órbita e sobrecodificando todo o mercado do crime. Talvez essa afirmação, pensada para o caso do Rio de Janeiro, possa ser extensiva com alguma ressalva a São Paulo. Em terras paulistas, o roubo ocupa ainda uma centralidade maior nas dinâmicas organizacionais do "comando" do que em terras cariocas, mas certamente o tráfico exerce também um grande poder de articulação dos ilegalismos populares ${ }^{3}$.

3. A relação entre tráfico de drogas e roubo é um tema à parte que deve ser tratado de forma muito crite- 
Tanto no Rio de Janeiro como em São Paulo, desencadeou-se um processo de organização da criminalidade em "comandos" ou "facções" a partir do sistema prisional, no interior do qual se formaram coletivos com o intuito de regular o convívio entre presos e canalizar as demandas dirigidas à administração penitenciária. Cabe notar, entretanto, que o surgimento do Comando Vermelho (cv) - conhecido por inaugurar uma nova maneira de se organizar - iniciou-se em $1975^{4}$, ao passo que o Primeiro Comando da Capital (PCC) parece ter sido fundado no ano de 19935, quase vinte anos depois. Em ambos os estados, houve um lapso temporal entre o surgimento dos "comandos" e a expansão de sua influência para os mercados ilegais em favelas e bairros populares. O CV tornou-se amplamente conhecido ao longo da década de 1980, quando grandes assaltos foram atribuídos aos seus integrantes, mas somente no final dessa década constatou-se o controle das facções prisionais sobre as redes do varejo de drogas em favelas do Rio de Janeiro (Misse, 2003). Já a existência do PCC foi tornada pública apenas em 2001, quando ocorreram rebeliões simultâneas em 29 estabelecimentos prisionais. Cinco anos mais tarde, o PCC demonstraria também a sua influência extramuros, no episódio que ficou conhecido como "ataques do PCC" (Adorno e Salla, 2007) ou os "crimes de maio" (Mães de Maio, 2011).

A origem comum dos "comandos" e a vinculação com o tráfico de drogas como fonte de recursos econômicos para a reprodução de suas estruturas organizacionais, por si só, possibilitam estabelecer algumas analogias entre Rio de Janeiro e São Paulo. Mas, embora a abstração concreta do "crime organizado" nos permita aproximar os comandos carioca e paulista pela sua incongruência empírica, no nível de detalhamento em que procuramos trabalhar, os coletivos que realizam a venda de drogas em escala varejista nos parecem muito diferentes. Para iluminar esses contrastes, destacaremos as figuras do "dono do morro" no caso do Rio de Janeiro e do "patrão" em São Paulo, enfatizando as diferentes implicações das competências associadas, respectivamente, à "posse" e à "chefia” para a configuração do varejo de drogas em cada cidade. Para os efeitos deste texto, interessa pensar as aproximações e os distanciamentos desses coletivos estritamente no que diz respeito às atividades de

riosa em outro momento. De fato, as relações entre os diversos ilegalismos parecem ser um ótimo termo para se pensar sobre as diferenças entre Rio de Janeiro e São Paulo.

4. Ano em que foi fundada a Falange da LSN - referência à Lei de Segurança Nacional -, que passaria a chamar-se Falange Vermelha em 1976 e ganharia maior projeção a partir de 1979, quando foi batizada pela imprensa como Comando Vermelho (Lima, 1991).

5. Karina Biondi enfatiza que o chamado massacre do Carandiru em 1992 é um episódio muito importante para compreender a emergência do PCC; também ressalta que há diversas versões para a "origem do PCC", mas que ficaram encobertas pelo episódio do dia 31 de agosto de 1993. Para uma descrição, ver Biondi (2010) e Dias (2013). 
venda varejista de drogas - o chamado "movimento" (Misse, 2003) - e referimo-nos particularmente aos pontos de venda situados nos bairros mais pobres das cidades, objeto de nossas pesquisas empíricas e da observação direta, e que nos parecem os mais comuns em São Paulo e no Rio de Janeiro.

Os dados de campo indicam que o "movimento" nas duas cidades se organiza em um jogo de escalas locais e translocais, por coletivos que atuam de forma complexa, mobilizando relações horizontais e hierárquicas inseridas em dinâmicas políticas e econômicas. Um certo senso comum de base por vezes jornalístico e por vezes acadêmico sugere outras imagens: aquela de organizações "mafiosas" ou "cartelizadas", em que essa estrutura piramidal e centralizadora "dominaria” o tráfico de drogas por toda a cidade pelos desmandos tirânicos ou os cálculos dos agentes econômicos de seus "líderes".

Claro está que essas imagens são mais coerentes com o inimigo (racional ou irracional) a ser eliminado do "crime organizado" do que com as práticas verificáveis por trabalhos de pesquisa mais detidos. Mas não se trata aqui de retomar as críticas contra a noção de "crime organizado" (Barbosa, 1998; Telles e Hirata, 2010), esse "fantasma” (Misse, 2006) que habita uma série de políticas de controle do tráfico de drogas de cunho militarista (Graham, 2008) e alimenta os mercados bélicos e a aproximação das áreas da defesa e segurança nacional (Bigo, 2000), atualizando formas governamentais do passado e do presente (Sanjurjo e Feltran, 2015).

A existência prática da representação da violência urbana parece produzir uma mecânica que organiza o modo como os mercados do "crime" irão funcionar no bojo da necessária relação com as forças da ordem e, como consequência, atua intensamente na gestão das mortes da população pobre nas duas cidades. Trata-se de um dispositivo de governo ao mesmo tempo conjunto e conflitivo, produzido nas tramas das interações decisivas entre os operadores das instituições estatais e atores dos coletivos criminais (Hirata, 2014), uma dinâmica de "formas de governo que produzem crime e de dinâmicas criminais que produzem governo" (Feltran, 2011).

No que diz respeito às linhas mais gerais dessa relação, em uma perspectiva comparativa entre Rio de Janeiro e São Paulo, seguimos algumas sugestões de Gabriel de Santis Feltran ${ }^{6}$. Do ponto de vista das políticas de segurança pública, o estado de São Paulo procedeu nas últimas décadas a um processo de encarceramento em massa ${ }^{7}$ que resultou na maior população carcerária - 219.053 presos - e na segunda maior

6. O trecho segue a iluminadora formulação de Gabriel Feltran, feita em comunicações pessoais aos autores, a quem agradecemos imensamente pela direção apontada. Claro está que a responsabilidade de possíveis equívocos cabe evidentemente somente aos autores.

7. Para uma revisão histórica, ver Salla $(2007,2006)$; para uma análise da atualidade, ver Godoi (2015) e também Minhoto (2002). 
taxa de aprisionamento do país - 497,4 presos por 100 mil habitantes - (Depen-MJ, junho de 2014), ao passo que no Rio de Janeiro - onde a taxa de aprisionamento também aumentou, mas permanece abaixo da média nacional - predomina a alta letalidade da ação policial (Cano, 1997; Misse et al., 2013) decorrente das frequentes operações de incursão em favelas. Do ponto de vista dos coletivos criminais, encontramos segmentos opostos competindo pelos espaços prisionais e territórios para a venda de drogas no Rio de Janeiro e uma hegemonia de um único comando em São Paulo, nas prisões e nos bairros da cidade.

O resultado de tal conformação do dispositivo conjunto e tenso de regulação de mercados e gestão das mortes é expresso na diferença como o termo "pacificação" ganha significado em cada cidade. No Rio de Janeiro, o termo aparece associado à política de ocupação militarizada de favelas por meio das Unidades de Polícia Pacificadora (UPP), ao passo que, em São Paulo, o termo "pacificação" faz alusão à prática da "bandeira branca" levada a cabo pelo PCC e que teria contribuído para fazer despencarem as taxas de homicídio ${ }^{8}$.

Interessa-nos neste texto discutir como a configuração do "movimento" nos ajudaria a entender esses apontamentos gerais para além das estereotipadas imagens da violência urbana. Com o objetivo de comparar o mercado varejista de drogas em São Paulo e no Rio de Janeiro, partimos de diferenças empíricas, concentrando-nos nas figuras do "patrão" e da "sintonia" em São Paulo e do "dono do morro" e da "amizade" no Rio de Janeiro. Para tanto, foi necessário situar-se no cruzamento de três dimensões: as formas do "movimento" e da territorialização da venda de drogas nas duas cidades, as diferenças entre os coletivos de traficantes e as distintas relações entre traficantes e os agentes das forças da ordem. Mais do que trabalhar de forma exaustiva cada uma dessas dimensões, a ideia aqui será pensar os seus pontos de conexão e imbricação com vistas a entender esse tipo peculiar da economia urbana e suas consequências sociais e políticas.

\section{Os lugares de mercado do tráfico}

As redes do tráfico de drogas podem ser descritas na sua conformação mais generalizante por meio de uma "geometria de escalas variáveis", articulando comerciantes atacadistas e varejistas. São compostas por diversos grupos de tamanho e complexidade variáveis e articulações singulares quanto ao lucro, ao risco e às negociações, que permitem "tornear a lei" a fim de fazer circularem as mercadorias comercializadas

8. Hipótese defendida por pesquisadores como Gabriel Feltran, Daniel Hirata, Vera Telles, Karina Biondi, Adalton Marques, Camila Dias e outros. 
(Barbosa, 2005). Há tráfico nos bairros pobres ou ricos das cidades, havendo variações significativas nas dinâmicas desse comércio, em função das diferentes circunstâncias em que se desenvolve'. Mas, como já foi dito, nos interessam aqui especificamente as redes do varejo de drogas em favelas e bairros de periferia de São Paulo e Rio de Janeiro, aqui pensadas tendo por referência os trabalhos de campo dos autores em alguns desses lugares.

Essas redes apresentam-se, até certo ponto, de modo bastante semelhante nas duas cidades. As "biqueiras" paulistas e as "bocas de fumos" cariocas são pontos de venda de drogas territorializados e facilmente identificáveis pelos compradores, o que em ambos os casos implica, de um lado, a necessidade de negociar um "alvará de funcionamento" (Barbosa, 2005; Hirata, 2010) com as forças de ordem e, de outro, o desenvolvimento de estratégias de segurança, que se distinguem em boa medida em cada cidade. Guardadas as diferenças de escala a serem explicitadas adiante, observa-se nos dois contextos que as empresas locais do tráfico - chamadas "firmas" - apresentam hierarquias caracterizadas pela relação patrão/empregados e uma diferenciação interna dos papéis desempenhados pelos envolvidos. Em ambas as cidades, as "firmas" configuram-se de modo semelhante ao "modelo empresarial" descrito por Johnson et al. (1992) em sua tipologia das redes do comércio de crack nos Estados Unidos.

Grosso modo, é mesmo possível afirmar que a distribuição de papéis assume feições bastante próximas, conservando também muitas das mesmas categorias nativas para designar as diferentes posições referentes às atividades exercidas. Os "patrões" - termo que também é empregado para designar os "donos" ou "frentes" de morro no Rio de Janeiro - são os proprietários dos negócios. Os "gerentes" são pessoas da máxima confiança do "patrão" e de grande prestígio social, incumbidas de organizar as atividades de venda que, por sua vez, são desempenhadas pelos "vapores”, cuja remuneração é feita através de pagamentos semanais fixos e definidos e/ ou do recebimento de porcentagens da venda (Malvasi, 2012; Grillo, 2013; Batista, 2015). Sobre São Paulo, Hirata (2010) menciona também a existência dos chamados "campanas", que ocupam as posições mais baixas na hierarquia da "biqueira" e que, assim como os "olheiros" e "fogueteiros" (Barbosa, 1998) do tráfico carioca, são responsáveis por alertar sobre a aproximação da polícia.

Mas entre os papéis desempenhados nas "bocas de fumo" do Rio de Janeiro há um que não encontra qualquer tipo análogo nas "biqueiras" paulistas: o "soldado", aquele que trabalha na "contenção" da "boca” (Barbosa, 1998; Misse, 2003), confrontando a polícia ou traficantes de outra facção em combate armado. O emprego

9. Ver, por exemplo, Grillo (2008), sobre traficantes de classe média, e Pereira (2003) sobre as redes de tráfico em Copacabana. 
de seguranças armados para desempenhar funções estritamente bélicas nos pontos de venda de drogas no Rio de Janeiro denota diferenças significativas com São Paulo, no que se refere à relação com o território e às forças da ordem e, mesmo, quanto aos sentidos assumidos pelos papéis de "patrão" e "gerente" em cada cidade.

É crucial para o entendimento dos modos como se configurou o "movimento" nas duas cidades o fato de que o PCC se consolidou como a facção hegemônica em São Paulo ${ }^{10}$, ao passo que no Rio de Janeiro, há mais de três décadas, grandes facções disputam a regulação dos espaços prisionais e do tráfico nas favelas, sendo elas, atualmente, o Comando Vermelho (Cv), Terceiro Comando Puro (TCP) e Amigos dos Amigos (ADA $)^{11}$. No Rio de Janeiro, os conflitos entre facções tornaram necessária a articulação de uma defesa armada das circunscrições de atuação do tráfico e aumentaram as expectativas de traição, contribuindo para que se disseminasse $o$ porte ostensivo de armas de fogo nas "bocas de fumo" e traficantes reivindicassem o poder de vigilância e punição em seus domínios. Quando contrastada com o caso paulista, a gestão militar dos territórios onde ocorre a venda de drogas no Rio de Janeiro - explicitada pelo emprego dos "soldados" - constitui o cerne de importantes diferenças na conformação interna das "firmas" e dos "comandos".

No Rio de Janeiro, o “patrão" dos negócios é o “dono do morro". Há uma ênfase na relação de posse sobre o território das favelas, pois a hierarquia de cada "firma" estrutura-se com base no direito inalienável do "dono do morro" sobre a exploração do comércio de drogas em uma dada região, o que é garantido pelo seu alinhamento com a facção (Grillo, 2013). A figura do "dono do morro" integra a história urbana do Rio de Janeiro e antecede até mesmo o tráfico de drogas. Ela aparece já nos primeiros relatos sobre as favelas cariocas, como o do jornalista Costallat ([1924] 1995), em que o "valente" Zé da Barra é descrito como o "chefe incontestável da favela". Em São Paulo, tal figura simplesmente não existe. Ao "patrão" da biqueira pertencem os negócios de um ou mais pontos de venda de drogas, mas não a favela ou o bairro em que eles se situam. O "patrão" paulista é certamente uma pessoa importante em qualquer bairro das periferias, mas é apenas "patrão", no sentido da relação de contratação que estabelece com seus funcionários.

Temos, portanto, que um morro no Rio de Janeiro tende a comportar vários pontos de venda pertencentes a um mesmo “dono”, ao passo que em São Paulo cada

10. Existem facções rivais ao PCC, como o Comando Brasileiro Revolucionário da Criminalidade (CRBC) e o Terceiro Comando da Capital (TCC), mas são pouquíssimas as prisões controladas por essas facções e inexpressiva a sua influência em bairros de periferia (Dias, 2013; Marques e Biondi, 2010).

11. Existem também as chamadas "milícias", grupos criminosos que atuam em áreas de moradia de baixa renda, controlando os mercados de serviços básicos, cobrando taxas de proteção e formando bases eleitorais para candidatos políticos. Sobre milícias, ver Cano e Duarte (2011). 
"firma" movimenta um único ponto de venda. Podem existir "donos de morro" com poucos pontos e "patrões" de vários pontos de venda, mas o que parece ser mais recorrente é a maior extensão territorial e complexidade organizacional no Rio de Janeiro (Grillo, 2013) e um comércio dinâmico, fluido e fragmentado no caso de São Paulo (Malvasi, 2012). Essa diferença de escala exige diferentes formas de operacionalização da venda, produzindo lugares de mercado (Braudel, 1996) distintos do varejo de drogas em cada cidade.

Como consequência da maior extensão territorial das "firmas" cariocas, encontramos também uma maior diversificação dos cargos ocupados dentro da estrutura empresarial local. Para assegurar a sua posse sobre os pontos de venda de drogas e manter o fluxo de retorno dos proventos do tráfico, o "dono do morro" procura formar uma base de alianças políticas no nível local. Embora a recorrência de espancamentos, banimentos e execuções sumárias produza um efeito dissuasivo contra delações, traições e o não pagamento de dívidas, o seu poder não se sustenta apenas pelo emprego reiterado da força. O "dono" distribui "cargos" de gerência variados - também chamados "responsas" - entre os traficantes com maior prestígio, oferecendo-lhes uma participação no lucro das vendas. Como muitos "donos de morro" se encontram presos ou residem fora de "suas" favelas, eles nomeiam um “responsável" ou "frente do morro" de sua máxima confiança, que assume todas as suas prerrogativas (Grillo, 2013).

Em "firmas" de maior porte, há abaixo do "frente" diferentes escalões de gerentes ou "responsáveis" - com atribuições variadas - chamados "responsas" -, como a aquisição e "endolação" de cada tipo de droga, a organização das "equipes" de "plantão" em cada "boca de fumo" e a gestão de cada "preço" de droga comercializado na "boca" (maconha de um, dois, cinco ou dez reais; cocaína de cinco, dez, quinze, vinte etc.). Desse modo, o "vapor" de "plantão" na "boca de fumo" centraliza a comercialização de cargas de drogas vendidas a uma variada gama de preços e geridas por uma série de gerentes. As posições de "vapor" e "soldado" podem ser fixas ou alternáveis, e os gerentes podem ter a atribuição de desempenhá-las também, mas quem atua apenas como "vapor" e/ou “soldado", em regime de plantão de doze horas, não possui ainda um "cargo" de confiança. (Grillo, 2013)

Já no caso das "firmas" paulistas, a diversidade da diferenciação interna é menor, havendo apenas os papéis de "patrão", "gerente", "vapor" e "campana", e existe uma flexibilidade ainda maior das posições, pois os patrões podem se dividir como responsáveis pela venda de cada tipo de droga, sendo as posições menos prescritas entre os gerentes e vendedores (Hirata, 2010; Batista, 2014). Dada a menor escala dos negócios locais, são mais restritos os cargos de gerência ocupados. Cada "vapor" lida apenas com um único gerente, que é seu contratante e com quem estabelece relações 
diretas de prestação de contas das vendas realizadas em cada plantão. As unidades de venda de cada droga são, portanto, comercializadas a um único preço. Diferentemente do Rio de Janeiro, onde a multiplicação das gerências constitui uma estratégia de manutenção da soberania sobre territórios, nas "biqueiras" paulistas, a nomeação dos gerentes está ligada basicamente à competência deles para a gestão dos negócios, ainda que tenha importância, em um raio de ação reduzido em comparação ao Rio de Janeiro, na rede de alianças que confere força aos seus membros em relação a outras alianças e no planejamento de outras atividades como o roubo, por exemplo.

Poderíamos dizer então que, do ponto de vista morfológico, a distribuição de drogas é muito distinta, porque a circulação de mercadorias ocorre em um caso tendo por base uma extensão organizacional e territorial que multiplica suas funções intermediárias e fragmenta progressivamente as quantidades de droga, enquanto a outra utiliza unidades de venda compactas e com pouca abrangência, que concentram a venda no aumento de sua densidade e volume na circunscrição territorial. Por essas razões é possível comprar uma "trouxinha" de até um real no Rio de Janeiro e em São Paulo não, assim como a concorrência via qualidade do produto pode ser feita de forma intraterritorial no Rio de Janeiro e somente de maneira interterritorial em São Paulo.

Em ambos os casos, é a centralidade da coerção que estabelece a fluidez na circulação de drogas e dinheiro, mas em um caso se trata de uma distribuição de propriedades e responsabilidades do "dono do morro" (Grillo, 2013) e no outro, de competências e atribuições feitas pelo "patrão" a seus funcionários (Hirata, 2010). Isso significa que a relação estabelecida entre o "dono do morro" e o "patrão" com os outros integrantes da firma é muito diferente. Em primeiro lugar porque a mobilidade interna à "firma" é feita de formas diferentes, ainda que tanto em São Paulo como no Rio de Janeiro isso ocorra levando em conta a "caminhada" (Marques, 2014) ou a "consideração" (Barbosa, 1998; Grillo, 2013) construída ao redor de uma história pessoal e uma memória coletiva (Hirata; 2010). A questão é que, no Rio de Janeiro, o "comando" assegura aos "donos do morro" a "posse inalienável" (Weiner, 2000) do tráfico, de modo que as concessões do direito de exploração comercial são coisas que circulam pelos sistemas de troca sem perder o vínculo com o proprietário original (Grillo, 2013). Em São Paulo, como contratantes, a exploração comercial pode ser feita em arranjos e desarranjos que não seguem necessariamente uma linhagem que remonta a um passado distante e, por isso mesmo, permite uma composição e recomposição das "firmas" de forma menos duradoura, sem que haja necessariamente confrontos por essa razão (Malvasi, 2012).

Em ambos os casos, parece-nos que o que está em jogo são lógicas de um movimento segmentar (Barbosa; 2001). Mas isso ocorre de forma extremamente diferente 
dependendo da dinâmica entre os "patrões" ou "donos de morro" e os comandos de cada cidade.

\section{Coletivos criminais}

Aqui podemos iniciar a segunda dimensão de nossa discussão acerca do tráfico varejista de drogas. Os comandos são compostos singulares feitos de matérias distintas. Assim, apesar de as segmentações serem comuns a ambas as cidades, a matéria e a dinâmica de suas composições e recomposições são muito diferentes, ou seja, a capacidade de romper a rede e se refazer no momento seguinte são semelhantes, mas se operacionalizam de forma diversa.

Nas duas cidades ocorrem tanto um alinhamento entre "firmas" que se aliam e crescem juntas como rupturas internas forjadas por traições ou alianças de parte do grupo com outros grupos. Uma hipótese a ser trabalhada é que, no caso do Rio de Janeiro, as rupturas internas e as alianças com outros grupos parecem ser menos recorrentes, ainda que com maior impacto na dinâmica dos comandos, ao passo que, em São Paulo, as quebras de alianças têm maior frequência, embora proporcionem um impacto muito menor no comando. Essa parece ser uma hipótese de trabalho mais matizada das explicações que se concentram apenas e exclusivamente na ideia da paz construída pelo monopólio do PCC em São Paulo e das guerras concorrenciais entre facções no Rio de Janeiro.

Em uma primeira aproximação, poderíamos dizer que os comandos presentes tanto no Rio de Janeiro como em São Paulo são redes horizontais de proteção mútua (Misse, 2003). Isso significa que a adesão a esses coletivos e os laços de que se constituem favorecem os seus integrantes nas situações de oposição aos seus "outros". Seja contra as péssimas condições de encarceramento, seja nos confrontos com policiais ou nas disputas com comandos rivais, a proteção em diferentes situações é o que produz a presença do coletivo. Além disso, a principal motivação para a organização da massa carcerária que resultou nos comandos foram as péssimas condições de encarceramento, que produziam ambientes dominados pelo medo e desconfiança, "não apenas da violência dos guardas, mas também da ação das quadrilhas formadas por presos para roubar, estuprar e matar seus companheiros" (Lima, 1991). As figuras do "alemão" no Rio de Janeiro e do "coisa” em São Paulo (Biondi, 2010) são o Outro dos comandos e favorecem a produção da identidade pela sua oposição e negação (Misse, 1999), operando como dispositivos de estabelecer fronteiras e contrastes, que iluminam a presença e a adesão ao comando.

Mas os princípios de inclusividade/exclusividade dos comandos diferem bastante em cada cidade. Ao contrário do PCC, cujos “irmãos” passam por procedimentos de 
"batismo" e devem contribuir com pagamentos mensais ao "Partido"12 no período em que estão fora da prisão (Dias, 2013), as facções cariocas não dispõem de nenhum protocolo claro de adesão de seus membros. No Rio de Janeiro, qualquer um que resida em uma área controlada por determinada facção, envolvido ou não com o tráfico local, pode evocar o pertencimento a ela, como afirmou Natasha Neri (2009) a respeito de adolescentes que cumpriam medida socioeducativa. A existência de rituais de "batismo" do PCC não implica, contudo, que a adesão ao comando seja menos fluida que no Rio de Janeiro. Por certo, a influência do PCC transborda para muito além de seus "irmãos", fornecendo referenciais de conduta para todos aqueles que alegam "correr lado a lado com o comando" (Biondi, 2010; Marques, 2015). Esse transbordamento se faz evidente na maneira pela qual o PCC se efetua nas instituições socioeducativas, por vezes mimetizado nas relações e nos enunciações dos adolescentes (Mallart, 2014). No entanto, a diferença entre "irmãos" e "primos" - isto é, entre o membro batizado e aquele que apenas "corre lado a lado" - estabelece distâncias e proximidades (Marques, 2010) que não existem de forma tão estanque no caso do Rio de Janeiro.

Nas favelas cariocas, todos aqueles que trabalham em uma "boca de fumo" automaticamente "fazem parte" de uma facção e podem ostentar esse pertencimento. Mas, embora o sentido de adesão à facção seja um elemento central da construção identitária dos engajados no "crime", quando o tráfico em uma região passa do controle de um comando a outro, todos os "bandidos" que ali permanecerem devem trocar a sua fidelidade, "pulando de facção". Isso porque a estrutura organizacional dos comandos cariocas se encontra diretamente atrelada ao varejo de drogas. Os comandos são redes de alianças entre "donos de morro" (Barbosa, 2005), cujo alinhamento com uma ou outra facção determina a adesão de todos os seus subordinados. A destituição do poder de um "dono" sobre os territórios que controla necessariamente envolve uma troca de comando, alcançada por meio da "guerra" ou do "golpe de estado" - como é chamada a tomada de poder por traficantes da própria "firma”, respaldados por uma facção inimiga.

O tráfico de drogas no Rio de Janeiro funciona segundo um conjunto de alianças que articulam grupos de nível local em um espaço permanente de negociações. Não há chefia "acima" dos "donos de morro", de modo que a hierarquia concerne apenas às atividades comerciais dentro dos limites territoriais de cada grupo (Barbosa, 2006). Assim, nesse nível local, o "dono do morro" mobiliza relações hierárquicas com seu grupo e, em nível supralocal, estabelece relações horizontais com seus aliados, cujo respaldo autentica a sua propriedade sobre os direitos de exploração do comércio de drogas em determinados territórios (Grillo, 2013).

12. Como é também chamado o PCC. 
Barbosa (1998) ressaltou a importância da "amizade" para entender o tráfico de drogas no Rio de Janeiro. A distribuição de áreas de atuação, a mobilidade de drogas, armas e homens sustentam-se pela dinâmica de alianças e segmentaridades, que atravessa a cidade, suas disputas e negociações. A hierarquia local da venda de drogas, cuja linha vertical seriam os "donos de morro", depende das alianças laterais de seus membros em postos superiores para se estruturar (Barbosa, 1998). O movimento e os processos de segmentação seriam efetuados mediante a composição/recomposição, acionamento/desligamento de amizades antigas. Assim, se um grupo local ganha prestígio e poder suficientes para romper com o comando do qual faz parte ou se romper internamente, os comandos acionam linhagens para reativar a sua presença no local; ou seja, pode-se formar um novo comando, podem-se rearranjar as relações entre os comandos ou pode-se minorar o centro de poder nascente.

Já em São Paulo, poderíamos dizer que a relação entre as alianças e as hierarquias em nível local e supralocal ocorre de modo semelhante, mas com a diferença de que a miríade de pontos de venda de drogas e seus "patrões" estabelece uma conformação muito mais fluida e dispersa. Essa diferença não é trivial, pois conforma um sistema de alianças formadora do comando composto por um número muito maior de "patrões" que de "donos de morro" e, portanto, mais móvel e translocal em São Paulo e com maior centralidade hierárquica e territorial no Rio de Janeiro.

Deve, contudo, ser ressaltado que o PCC não é propriamente uma facção do tráfico de drogas. É certo que, como comando hegemônico nas prisões e periferias de São Paulo, o PCC atua na regulação desse mercado que, por sua vez, constitui uma das principais fontes de renda de seus membros. Mas os "patrões” das “biqueiras” não são necessariamente "irmãos" do PCC, podendo também ser apenas "primos" (Malvasi, 2012). A estrutura organizacional do comando distingue-se das facções cariocas, na medida em que não corresponde diretamente às hierarquias empresariais do tráfico. Boa parte das alianças que compõem o PCC visa à prática de roubos, diferentemente do Rio de Janeiro, onde os assaltantes são mais "autônomos" em contraste com as relações de "assalariamento" do tráfico que compõem a hierarquia dos comandos (Lyra, 2013). Não à toa, o termo "responsa" - que no Rio de Janeiro se refere aos cargos de gerência nas "firmas" do varejo de drogas (Grillo, 2013) - designa, em São Paulo, posições políticas (Biondi, 2010) ou de liderança (Marques, 2014) assumidas por membros do PCC encarregados de assegurar a "disciplina do Comando" em cadeias e "quebradas", como o "disciplina”, "geral", "frente", "palavra", "piloto", “jet", "torre", "terminal” e "final” (Biondi, 2014, p. 185).

Nesse sentido, as reconfigurações de alianças e rivalidades entre os "patrões" do tráfico paulista não prejudicam a influência do PCC sobre os bairros ou "quebradas". Ao contrário do Rio de Janeiro, onde há conflitos entre grandes blocos segmentares 
pelo controle de territórios, o PCC arrefeceu as disputas entre as quadrilhas de traficantes que compõem o fragmentado mercado varejista de drogas paulista. Diante da drástica redução das taxas de homicídio evidenciada ao longo dos anos 2000, predominou entre os etnógrafos urbanos a tendência de argumentar que a diminuição das mortes violentas estaria associada à atuação do PCC na regulação dos mercados ilegais e na mediação de conflitos, o que ficou conhecido como a "hipótese PCC" (Lima, 2009). Daí a emergência de o termo "pacificação" estar associado à atuação desse coletivo.

Karina Biondi vem trabalhando de forma sofisticada a categoria "sintonia", que nos ajuda a entender as especificidades de São Paulo em relação ao contexto carioca. A autora propõe que pensemos o PCC como um "movimento" que se organiza também por conexões e "conhecimento" entre aqueles que "correm lado a lado", "somam" e "fecham" uns com os outros "na mesma caminhada". Tal conexão com o Comando e entre "ladrões", prisões e "quebradas" é chamada "sintonia”. Mas este não é apenas um nome diferente homólogo ou análogo a um tipo de conexão, pois a "sintonia" produz um "movimento" diferente. O termo possui uma acepção bem distinta em São Paulo daquela a que se referiu Misse (2003) sobre o Rio de Janeiro, onde "movimento" designa o varejo local de drogas. No caso do PCC, estar "no movimento" é estar em "sintonia" com o Comando, em ressonância com as "ideias" e as "responsas" que repercutem e são abraçadas (Biondi, 2014), independentemente de possuir ou não ligações com o tráfico ou mesmo de "estar no corre", isto é, praticando crimes. É ser produto e produtor do "crime", no sentido que Adalton Marques confere ao termo (Marques, 2010). Dessa forma, crime e criminoso não são categorias penais, tipificadas pelo código jurídico. Segundo a acepção de "crime" de Marques, pode-se "correr pelo crime" sem ser um número do código penal e, ao contrário, pode-se não correr mesmo sendo um número do código, como é o caso de policiais indiciados.

É assim que a "sintonia" deve ser compreendida, como um movimento mais amplo, como o "crime", fruto de muitos outros movimentos que a compõem, um movimento composto de muitos outros movimentos (Biondi, 2014). Biondi fala de três expressões da "sintonia", tomadas aqui analiticamente separadas, mas que compõem, articuladas, fluxos dos "movimentos" e "ideias": uma conexão entre "ladrões", parcerias de movimentos que conectam bairros, quebradas entre si e entre eles, nesses casos envolvendo ou não o PCC; o nome de uma relação que é produto e produtora do PCC e sua ética, sem necessariamente ser "integrante" ou "membro batizado"; por fim, estar em sintonia é “abraçar uma responsa”, zelando e resolvendo problemas que devem ser solucionados.

Talvez, como hipótese, poderíamos pensar como as diferenças na configuração do "movimento" se combinam de forma complexa com a maneira pela qual as co- 
nexões e as segmentações produzem comandos no Rio de Janeiro e São Paulo. Isso não significa que as facções determinem ou instituam a constituição e a diferença dos lugares de mercados (market places). A história urbana dos circuitos mercantis e dos coletivos criminais não autorizaria tal apontamento de causalidade. Mas nos parece congruente a associação de um mercado associado por "donos de morro" e suas relações de "amizade" e outro por "patrões" em "sintonia”. Isso porque as relações políticas e econômicas (se algum dia foi possível estabelecer essa separação) parecem produzir, de um lado, um espaço mais extenso e de grande densidade organizacional, afetado por blocos segmentares de aliança e rivalidade, e, de outro, um espaço mais compacto e disperso com articulações que efetuam ritmos com ressonâncias ou dissonâncias variáveis.

\section{Arranjos entre o tráfico, o território e as forças da ordem}

Para a compreensão etnográfica dos agenciamentos que permitem a circulação de drogas, enquanto mercadorias proibidas por lei, a interação decisiva se estabelece na relação entre os atores que participam desses mercados e os agentes imediatamente encarregados de seu controle. A situação que a proibição de certas substâncias institui faz da polícia o elemento-chave da regulação do mercado de venda de drogas - um dos mais lucrativos em qualquer bairro de periferias ou favelas das duas cidades. Dotados das prerrogativas que o Estado lhes confere, os agentes imediatamente encarregados do controle desse mercado não são apenas executores da lei, mas adquirem autonomia diante da autoridade central, por meio de triagens, seletividades, discricionariedades próprias e práticas negociadas localmente com os participantes alvos de seu controle (Gazit, 2009). Trata-se, portanto, de conflitos e negociações entre traficantes e policiais que agenciam conjuntamente um poder muito mais "tangencial" que "paralelo", como é comum aludir nas imagens associadas ao conceito de "crime organizado" (Barbosa, 2005).

$\mathrm{Na}$ linguagem nativa, essa interação decisiva entre agentes do controle e participantes dessa forma de economia popular é chamada de "acerto", "madeira” ou "pagar pau” em São Paulo e "arrego" no Rio de Janeiro. Mas tal dinâmica é aqui pensada também por meio do conceito de "mercadorias políticas". Segundo Michel Misse, o mercado de "bens políticos" é um mercado parasita que regula os mercados informais, ilegais e ilícitos, transacionando serviços cujo preço não depende apenas das leis de mercado, mas também "de avaliações estratégicas de poder, de recurso potencial à violência e de equilíbrio de forças" (Misse, 2006).

O conceito nativo/analítico de "ponto" (ponto de venda) pode ajudar a entender como a formulação de Misse relaciona formas econômicas e políticas na sua con- 
formação: resumidamente, poderíamos dizer que todo comércio (legal ou ilegal) é um ponto referido à aglomeração urbana com um certo valor-localização que estabelece a lucratividade de cada lugar por referência ao aglomerado urbano (Villaça, 1998); mas para que isso seja operante é necessária uma autorização (legal/ilegal) da venda, que pressupõe uma autoridade coercitiva e consensualmente instituída e dotada de prerrogativas que permitem a venda em um determinado lugar (Hirata, 2014). Contudo, em cada cidade, isso ocorre segundo lógicas muito distintas de espacialização das trocas (Rabossi, 2004). Descreveremos "qual o ponto", ou como se negocia "o ponto" em cada uma delas.

Em São Paulo, os grupos que realizam a venda não tentam se impor militarmente sobre uma certa área, não existem mais na cidade lugares onde os policiais "não entram” e em que o controle em última instância não pertença à polícia. Além disso, as estratégias de venda tendem à discrição e à negociação em relação aos policiais. As relações entre policiais e traficantes são construídas a partir da constatação inicial de que a força oficial, do ponto de vista militar, é muito superior e não se procura "atenuar" essa disparidade. Os cálculos estratégicos de força pressupõem a superioridade das forças do Estado. No território delimitado pelo perímetro de atuação de cada delegacia, a polícia tem um controle potencial e efetivo superior ao dos traficantes, adentrando o perímetro do ponto de venda de drogas quando desejam.

Por isso, a delegacia de polícia é o centro de controle da regulação da venda de drogas, governando esse mercado de forma soberana. É através dessa prerrogativa que, para que as mercadorias circulem, exigem o pagamento de duas formas de mercadoria política: "a compra do alvará de funcionamento" e a "extorsão por sequestro" (Hirata, 2014). No primeiro caso, paga-se pela "autorização" para operacionalizar o comércio em um determinado lugar; no segundo, depois de uma invasão do ponto de vendas e o sequestro de algum traficante, negocia-se o pagamento da liberação ou do "resgate".

No Rio de Janeiro, embora seja também evidente a larga superioridade do poder armado do Estado, os traficantes oferecem resistência às forças policiais que adentram suas circunscrições de atuação. Operações pontuais e relativamente imprevisíveis de incursão armada em favelas constituem o cerne de um modelo de regulação do mercado de drogas, que depende de não haver policiamento regular em porções territoriais taxadas como "áreas de risco" e relegadas ao controle armado de criminosos (Grillo, 2016). Mesmo antes de haver tráfico armado nas favelas cariocas, a polícia já não patrulhava rotineiramente esses espaços, o que se asseverou ao longo das últimas três décadas com a intensificação do fluxo de capitais em circulação proporcionada pela comercialização da cocaína (Misse, 2003). A reprodução das redes de varejo passou a depender do emprego de "soldados" armados para proteger os traficantes, 
as armas, as drogas e o dinheiro das sempre possíveis invasões, pilhagens e capturas perpetradas por policiais ou grupos de uma facção rival.

Assim como em São Paulo, ocorrem no Rio de Janeiro o pagamento do alvará de funcionamento ou "arrego" e a extorsão por sequestro ou "mineira" (Barbosa, 2005). Contudo, não há uma estabilização completa no jogo das trocas das mercadorias políticas, de modo que o pagamento do "arrego" não substitui os confrontos entre polícia e tráfico. As operações de incursão em favelas são ainda o principal método policial de regulação do "crime", servindo tanto para medir a capacidade de resistência dos traficantes e impor a necessidade de negociação, como para retaliar a "firma" por homicídios ou roubos ocorridos em uma dada região. Desse modo, as avaliações estratégicas de poder potencial, de recurso potencial à violência e de equilíbrio de forças assumem um papel central na conformação das rotinas do tráfico.

Se a imagem espetacularizada do Rio de Janeiro sempre foi a de meninos sem camisa, tênis e fuzil defendendo a "firma”, ela tem plausibilidade na comparação com São Paulo, onde a venda ocorre de forma mais discreta, sem utilização de mesas na rua para apoiar as cargas de droga ou armas à mostra para a proteção do perímetro do local onde ocorre o comércio. As armas (inclusive fuzis e granadas) estão também presentes nas ruas paulistas, mas são raramente usadas para a "contenção" de operações policiais, sendo mais recorrentemente emprestadas ou alugadas em momentos de grandes roubos ou usadas em acertos de contas.

No entanto, é equivocado supor que não ocorram conflitos entre policiais e traficantes em São Paulo. A incidência dos casos registrados como "resistência seguida de morte" vem crescendo e já superou o Rio de Janeiro em números absolutos no ano de $2014^{13}$, embora as taxas continuem bastante inferiores. Pinheiro et al. (1991) assinalaram a alta incidência de mortes em conflitos com policiais ainda no período entre 1981 e 1989. Tais conflitos, contudo, não resultaram em descontinuidades militares no tecido urbano, podendo as viaturas policiais circular regularmente por todo o território metropolitano. Mais do que os homicídios cometidos por policiais em serviço, chama a atenção em São Paulo a recorrência de chacinas atribuídas pela população a policiais descaracterizados. Elas são interpretadas pelos moradores de bairros de periferia como vinganças pela morte de policiais, supostamente assassinados a mando do PCC. Esse tipo de chacina ocorreu com mais frequência no Rio de Janeiro durante a década de $1990^{14}$. No século vigente, as vinganças têm se utilizado

13. Segundo dados da Secretaria da Segurança Pública do Governo do Estado de São Paulo, no ano de 2014, houve 518 "pessoas mortas em confronto com a polícia militar em serviço" e onze em confronto com a Polícia Civil, na capital e Grande São Paulo. Dados disponíveis em http://www.ssp.sp.gov.br/ novaestatistica/Trimestrais.aspx, consultados em 9/4/2015.

14. Como a chacina de Acari em 1990 e as chacinas da Candelária e Vigário Geral em 1993. 
mais frequentemente de operações formais que resultam em diversas mortes, porém integram o corpus estratégico das políticas de segurança pública.

Nos últimos anos, tentou-se modificar os padrões da relação entre polícia e tráfico nas favelas cariocas, onde "guerras" e tiroteios obrigam os moradores a conduzirem as suas rotinas no "fogo cruzado" entre a violência de ambas as partes (Machado da Silva e Leite, 2008). A implantação de U PPs em algumas regióes buscou substituir o modelo das operações tópicas de incursão policial por ocupações estáveis em favelas, o que implicou mudanças morfológicas na operacionalização da venda de drogas. A repressão ao tráfico e a segurança das "bocas de fumo", antes geridas pela alternância entre o confronto armado e o pagamento do "arrego", passaram a depender mais das práticas de monitoramento recíproco da circulação de traficantes e policiais pela favela (Menezes, 2015). Mas ainda que tenha diminuído o porte ostensivo de armas de fogo e muitas "bocas" tenham se tornado mais móveis, o tráfico conservou seus moldes territorializados de atuação. Segundo Palloma Menezes (2015), as upps converteram o "regime de fogo cruzado" em um "regime de campo minado", caracterizado pela redução da incidência de conflitos violentos ao custo de uma elevação das tensões latentes.

Seria tão enganoso pensar que a venda de drogas no Rio de Janeiro está se tornando parecida com a de São Paulo por meio do "regime de campo minado", quanto prever o necessário desmembramento do PCC em outros comandos pelo simples fato de que assim aconteceu no Rio de Janeiro. Além de a dinâmica da venda, a conformação dos coletivos criminais e as relações com a polícia serem diferentes nas duas cidades, a conjunção dessas três dimensões é singular em cada lugar. Nada nos autorizaria a dizer que uma ou outra cidade é um momento do futuro e do passado em uma linha necessária que uma ou outra cidade deve seguir. Pelo contrário, os caminhos parecem suficientemente distintos para que as transformações em cada cidade sejam muito distintas.

\section{Considerações finais}

A venda de drogas é um ilegalismo muito específico, porque a incidência repressiva é a mais extensiva e a exposição à morte a mais intensiva. De um lado, ele é duplamente criminalizável, pois se trata de um mercado informal - não regulado formalmente - que faz circular mercadorias ilícitas, condição que o torna alvo de repressão extensiva. De outro lado, a exposição à morte é a mais intensiva por uma série de fatores que incluem o seu significado contextual para a ordem pública, a reação moral da sociedade e a sua possível ou imaginária afinidade com outras mercadorias e práticas criminalizadas (Misse, 2006). A combinação de repressão 
extensiva com exposição à morte intensiva faz a especificidade da venda de drogas e constitui as formas particulares do seu agenciamento.

Como vimos no início, a política de encarceramento em massa produziu impactos em São Paulo muito distintos das políticas de enfrentamento e ocupação militar, de que o programa das UPPs é somente o ponto de chegada até o momento no Rio de Janeiro. De um ponto de vista político, escolher entre indivíduos encarcerados ou mortos não nos parece um bom termo para pensar em ações voltadas à questão das drogas; de um ponto de vista analítico, conformam maneiras distintas de governar aqueles considerados ingovernáveis. Como já ressaltado por Karina Biondi, o encarceramento em massa foi (associado aos massacres nas ruas e nas prisões) um fator que impulsionou o crescimento do PCC. No caso do Rio de Janeiro, o enfrentamento somente aumentou as rivalidades faccionais e, no conjunto, fez crescer a importância de cada uma delas.

O exercício de estabelecer comparações da venda de drogas no Rio de Janeiro e em São Paulo foi pensado para prospectar esses diferentes dispositivos de gestão das mortes por meio daqueles que são seu objeto de incidência governamental. Para tanto, propusemos três dimensões analíticas que, combinadas de múltiplas formas, nos parecem pertinentes para colocar o tema em discussão: o espaço da venda de drogas, as dinâmicas dos coletivos criminais e a relação com as forças da ordem. O arranjo entre "guerra e paz" nas relações (inter e intra) faccionais e com os policiais assim como a articulação entre "circulação e bloqueios" das mercadorias são efetivados de formas diferentes em cada uma das cidades. Parece-nos que são essas as diferenças que delineiam as questões mais centrais que envolvem o comércio varejista de drogas.

A venda extensiva, fracionária e densa no arranjo carioca difere do comércio restrito, compacto e fluido dos paulistas; a hierarquia local e as alianças laterais do CV e da ADA são distintas da horizontalidade e da supralocalidade do PCC; a dinâmica de segmentação e alianças é impulsionada pela amizade no Rio de Janeiro, diferentemente da sintonia em São Paulo; a alternância entre negociações nas prisões e demonstrações de força via chacinas ou assassinatos seletivos tem predominância distinta em cada cidade. No encontro dessas linhas, a trama das relações entre o mercado varejista de drogas, a lógica da coerção e a produção das mortes ganha contornos muito particulares em cada uma das cidades.

Encontramos então guerras diferentes, mas com maior letalidade no Rio de Janeiro, dado que o enfrentamento entre os diferentes comandos entre si e com a polícia é uma máquina mais mortífera que a política de "paz entre os ladrões" do PCC, feita dentro e fora das prisões. Internamente, o que parece comum e decisivo em cada uma dessas composições e políticas dos coletivos criminais são as tensões 
entre linhas que procuram estabelecer a centralização e a hierarquia intrafaccional e aquelas que apontam para uma maior horizontalidade nessas relações. Mas, no que diz respeito ao comércio de drogas, tanto as combinações singulares entre exércitos posicionados frente a frente na disputa por territórios como os movimentos táticos e sub-reptícios dispersos produzem, ambos, mortes de geração em geração que alimentam a própria mecânica do extermínio das populações mais pobres.

A relação com as polícias, apesar de ser muito semelhante nas duas cidades, aciona no Rio de Janeiro contornos intra e interfaccionais que em São Paulo parecem ter um equacionamento distinto, acentuando-se as negociações intramuros seguidas de demonstrações de força no caso paulista e confrontos por regiões mais lucrativas com impactos nas prisões no Rio de Janeiro. Não se trata aqui de fazer um levantamento para saber qual a polícia que se encontra mais imersa nos jogos de forças das mercadorias políticas, mas sim, como tentamos esboçar, quais as diferentes formas de agenciar essa relação. Para isso é necessário levar em consideração dois aspectos: de um lado, os mercados políticos são formas de permitir que os mercados funcionem, pois tornam mais fluida a circulação de mercadorias cuja comercialização é proibida; de outro, potencializam a segmentação desses coletivos e sua disposição para o confronto com os próprios policiais, aumentando as tensões potenciais e efetivas, que se tornam visíveis quando dos confrontos com visibilidade midiática. Nessa direção, as formas de circulação são processadas, como exposto ao longo do texto, em volumes distintos na sua distribuição varejista, o que acentua a negociação da mercadoria política varejista, para o caso de São Paulo, e mercadoria política atacadista no Rio de Janeiro ${ }^{15}$. O rompimento dessas negociações tem, portanto, impactos muito distintos no delicado equilíbrio político e econômico de cada cidade. $\mathrm{O}$ impacto de negociações das mercadorias políticas no varejo das drogas no Rio de Janeiro é muito maior, já em São Paulo, onde o sistema prisional parece responder nas ruas às negociações das prisões, o varejo segue o mesmo ritmo ditado pela venda dispersa.

Esses breves apontamentos seguem mais como hipóteses de pesquisa do que como conclusóes. Somente a pesquisa que vem sendo conduzida pelos autores e a interlocução com um campo expansivo de excelentes pesquisas em andamento poderão apontar a validade ou o desdobramento dessas considerações provisórias.

15. Para uma discussão sobre mercadorias políticas atacadistas e varejistas, em outro contexto de pesquisa, ver Hirata (2015). 


\section{Referências Bibliográficas}

Adorno, Sérgio \& SAlla, Fernando. (dez. 2007), “Criminalidade organizada nas prisões e os ataques do PCC”. Estudos Avançados, 61 (21): 7-29.

Batista, Liniker Giamarim. (2014), A grande cidade e a vida no crime: uma etnografia dos mercados do crime em uma periferia de São Paulo. Campinas, dissertação de mestrado, Programa de Pós-graduação em Antropologia Social da Universidade Estadual de Campinas.

Barbosa, Antonio Carlos Rafael. (1998), “Um abraço para todos os amigos: algumas considerações sobre o tráfico de drogas no Rio de Janeiro”. Niterói, Eduff.

. (2005), Prender e dar fuga: biopolítica, sistema penitenciário e tráfico de drogas no Rio de Janeiro. Rio de Janeiro, tese de doutorado, Programa de Pós-Graduação em Antropologia Social do Museu Nacional da Universidade Federal do Rio de Janeiro.

Biondi, Karina. (2010), Junto e misturado: uma etnografia do PCC. São Paulo, Terceiro Nome. . (2014), Etnografia no movimento: território, hierarquia e lei no PCC. São Carlos, tese de doutorado, Programa de Pós-graduação em Antropologia da Universidade Federal de São Carlos.

BraUdel, Fernand. (1996), Civilização material, economia e capitalismo. São Paulo, Martins Fontes. Cano, Ignácio. (1997), Letalidade da ação policial no Rio de Janeiro. Rio de Janeiro, Iser. \& DUARTE, Thais. (2012), 'Os donos do morro': uma avaliação exploratória do impacto das unidades de policia pacificadora (UPPS) no Rio de Janeiro. Rio de Janeiro, Fórum Brasileiro de Segurança Pública. Disponível em http://www.lav.uerj.br/docs/rel/2012/Relatupp.pdf, consultado em 15/2/2014.

Costallat, Benjamim. (1995), “A favela que eu vi”. In: (org.). Mistérios do Rio. Rio de Janeiro, Secretaria Municipal de Cultura, Departamento Geral de Documentação e Informação Cultural, Divisão de Editoração.

Departamento Penitenciário Nacional, Ministério da Justiça. (2014), Levantamento Nacional de Informações Penitenciárias - Infopen. Disponível em http://www.cnj.jus.br/ files/conteudo/arquivo/2015/11/080f04f01d5b0efebfbcf06d050dca34.pdf , consultado em $14 / 2 / 2016$.

Dias, Camila Caldeira Nunes. (2013) PCC: hegemonia nas prisões e monopólio da violência. São Paulo, Saraiva.

Feltran, Gabriel de Santis. (2010), “Crime e castigo na cidade: os repertórios da justiça e a questão do homicídio nas periferias de São Paulo”. Caderno CRH, 58 (23): 59-73.

(2011), Fronteiras da tensão: politica e violência nas periferias de São Paulo. São Paulo, Editora da Unesp.

GAzIT, Nir. (2009), "Social agency, spatial practices, and power: the micro-foundations of fragmented sovereignty in the occupied territories". International Journal of Politics, Culture and Society, 22 (1): 83-103. 
Godor, Rafael. (2015), Fluxos em cadeia: as prisões em São Paulo na virada dos tempos. São Paulo, tese de doutorado, Programa de Pós-graduação em Sociologia da Universidade de São Paulo. Graham, Stephen. (2010), Cities under siege. Londres, Verso.

Grillo, Carolina Christoph. (2008), “O 'morro' e a 'pista’: Um estudo comparado de dinâmicas do comércio ilegal de drogas". Dilemas: Revista de Estudos de Conflito e Controle Social. Rio de Janeiro, 1 (1): 127-148.

- (2013), Coisas da vida no crime: tráfico e roubo em favelas cariocas. Rio de Janeiro, tese de doutorado, Programa de Pós-graduação em Sociologia e Antropologia da Universidade Federal do Rio de Janeiro.

. (2016), "Fronteiras tácitas: confronto e acordo em favelas do Rio de Janeiro". Confins: Revista Franco-Brasileira de Geografia, 28: [s.p.]. Disponível em https://confins.revues.org/11246.

Hirata, Daniel Veloso. (2010), Sobreviver na adversidade: entre o mercado e a vida. São Paulo, tese de doutorado, Faculdade de Filosofia e Ciências Sociais da Universidade de São Paulo. (2014), “O ponto e a biqueira: notas para a construção de um conceito.” In: BARREIRA, César et al. (orgs.). Violência, ilegalismos e lugares morais. Campinas, Pontes Editores. . (2015), “Comércio ambulante no Rio de Janeiro e em São Paulo: grupos de poder e instrumentos de governo contemporâneos de governo". In: BIRMAN, Patrícia et al. (orgs.). Dispositivos urbanos e a trama dos viventes: ordens e resistências. Rio de Janeiro, Editora FGV. Johnson, Bruce et al. (1992), "Emerging models of crack distribution”. In: MiEczKOwsKi, Tom (org.). Drug, crime and social policy: research, issues and concerns. Boston, Ally and Bacon.

Leite, Márcia Pereira. (2000), "Entre o individualismo e a solidariedade: dilemas da política e da cidadania no Rio de Janeiro”. Revista Brasileira de Ciências Sociais, 44 (15): 43-90.

Lima, Renato Sérgio de. (2009), “Criminalidade violenta e homicídios em São Paulo: fatores explicativos e movimentos recentes". Trabalho apresentado no seminário "Crime, Violência e Cidade". São Paulo, Universidade de São Paulo, Programa de Pós-graduação em Sociologia-USP e NEV.

Lima, William da Silva. (1991), Quatrocentos contra um: uma história do Comando Vermelho. Rio de Janeiro, Vozes.

Lyra, Diogo. (2013), A República dos Meninos: juventude, tráfico e virtude. Rio de Janeiro, Mauad X.

Machado da Silva, Luis Antonio. (1999), “Criminalidade violenta: por uma nova perspectiva de análise”. Revista de Sociologia e Politica, 13: 115-124.

(2008), "Violência urbana, sociabilidade violenta e ordem agenda pública" In:

(org.). Vida sob cerco: violência e rotina nas favelas do Rio de Janeiro. Rio de Janeiro, Nova Fronteira.

\& LeITE, Márcia Pereira. (2008), "Violência, crime e polícia: o que os favelados dizem”. In: _. (org.). Vida sob cerco: violência e rotina nas favelas do Rio de Janeiro. Rio de Janeiro, Nova Fronteira. 
Mães de Maio (2011), Do luto à luta. (mimeo).

Mallart, Fábio. (2014), Cadeias dominadas: a Fundação Casa, suas dinâmicas e as trajetórias de jovens internos. São Paulo, Terceiro Nome.

Malvasi, Paulo Arthur. (2012), Interfaces da vida loka: um estudo sobre jovens, tráfico de drogas e violência em São Paulo. São Paulo, tese de doutorado. Faculdade de Saúde Pública da Universidade de São Paulo.

MARQues, Adalton. (2014), Crime e proceder: um experimento antropológico. São Paulo, Alameda.

Menezes, Palloma. (2015), Entre o "fogo cruzado" o o "campo minado": uma etnografia do processo de 'pacificação' de favelas cariocas. Rio de Janeiro, tese de doutorado, Instituto de Estudos Sociais e Políticos da Universidade do Estado do Rio de Janeiro.

Minhoto, Laurindo. (2002), "As prisões do mercado". Lua Nova, 55-56: 133-154.

Misse, Michel. (1999), Malandros, marginais e vagabundos: a acumulação social da violência no Rio de Janeiro. Rio de Janeiro, tese de doutorado, Iuperj.

(2003), "O Movimento: a constituição e reprodução das redes do mercado informal ilegal de drogas a varejo no Rio de Janeiro e seus efeitos de violência”. In: BAPTisTA, Marcos et al (orgs.). Drogas e pós-modernidade 2. Rio de Janeiro, Eduerj.

(2006), Crime e violência no Brasil contemporâneo: estudos de sociologia do crime e da violência urbana. Rio de Janeiro, Lumen Juris.

et al. (2013), Quando a policia mata: homicídiospor "auto de resistência" no Rio de Janeiro (2001-2011). Rio de Janeiro, Booklink.

Pereira, Luis Fernando Almeida. (2003), De olhos bem abertos: rede de tráfico em Copacabana. Rio de Janeiro, Editora FGV.

Pinheiro, Paulo Sérgio et al. (1991), "Violência fatal: conflitos policiais em São Paulo (19811989)”. Revista USP, 9: 95-112 [Dossiê Violência].

Rabossi, Fernando. (2004), "Dimensões da espacialização das trocas: a propósito de mesiteros e sacoleiros em Ciudad del Este”. Ideação, 6 (6): 151-176.

SAlla, Fernando. (2007), "De Montoro a Lembo: as políticas penitenciárias de São Paulo". Revista Brasileira de Segurança Pública, 1 (1): 72-90.

. (2006), "As rebeliões nas prisões: novos significados a partir da experiência brasileira”. Sociologias. 8 (16): 274-307.

Sanjurjo, Liliana \& Feltran, Gabriel. (2015), "Sobre lutos e lutas: violência de Estado, humanidade e morte em dois contextos etnográficos”. Ciência e Cultura, 2 (67): 40-45.

Telles, Vera da Silva. (2010), Cidade na fronteira do legal e ilegal. Belo Horizonte, Argumentum. \& Hirata, Daniel Veloso. (2010), "Ilegalismos e jogos de poder em São Paulo”. Tempo Social, 2 (22): 39-59.

Villaça, Flávio. (1998), Espaço intraurbano no Brasil. São Paulo, Studio Nobel/Lincoln Institute. WeIner, Annete. (1992), Inalienable possessions: the paradox of keeping-while giving. Oxford, University of California Press. 


\section{Resumo}

Sintonia e amizade entre patrões e donos de morro: perspectivas comparativas entre o comércio varejista de drogas em São Paulo e no Rio de Janeiro

Neste artigo será esboçada uma comparação do mercado varejista de drogas em favelas e bairros de periferias das cidades de São Paulo e Rio de Janeiro. As reflexões aqui apresentadas baseiam-se no trabalho de campo etnográfico realizado nas duas cidades, bem como na revisão de estudos sobre o tema. Ancorado em pesquisas empíricas, explora a mecânica das relações entre os mercados do "crime" e as forças da ordem, envolvida na gestão da vida e morte da população pobre. Em face das guerras concorrenciais entre facções cariocas e da ideia de paz associada à hegemonia de um único comando em São Paulo, a comparação concentra-se nas figuras do "dono do morro" e da "amizade" no Rio de Janeiro e do "patrão" e da "sintonia" em São Paulo, atentando-se para o cruzamento de três dimensões: os lugares de mercado do varejo de drogas; as dinâmicas dos coletivos criminais; e os distintos arranjos de poder estabelecidos entre os traficantes e os agentes das forças da ordem. Palavras-chave: Tráfico de drogas; Favela; Periferia; São Paulo; Rio de Janeiro.

\section{Abstract}

Comparative perspectives on the retail drug markets in São Paulo and Rio de Janeiro

This paper outlines a comparison of the retail drug market in favelas and peripheries of the cities of São Paulo and Rio de Janeiro. The reflections here presented are based in ethnographical field work conducted in both cities and a review of the studies on the theme. Anchored in empirical research, it explores the mechanics of relations between "crime" markets and forces of order, involved in the govern of life and death of the poor. Faced with violent competition among Rio's factions and the idea of peace associated to the hegemony of a single commando in São Paulo, the comparison concentrates on the figures of the "hill owner" and "fellowship" in Rio de Janeiro, and the "boss" and "attunement" in São Paulo, regarding the intersections between three dimensions: the market places of the retail drug market; the dynamics of criminal collectives; and the distinct power arrangements settled between drug traffickers and law enforcement agents. Keywords: Drug trafficking; Favela; Periphery; São Paulo; Rio de Janeiro.

Texto recebido em 12/1/2017 e aprovado em 9/2/2017. DoI: 10.11606/0103-2070.ts.2017.12 5494.

DANiel Veloso hiRATa é professor adjunto do Departamento de Sociologia e Metodologia em Ciências Sociais da Universidade Federal Fluminense. E-mail: velosohirata@gmail.com. CAROLINA CHRISTOPH grillo é bolsista de pós-doutorado Fapesp do Departamento de Sociologia da Universidade de São Paulo. E-mail: carolina.c.grillo@gmail.com. 
